\title{
Tuberculosis in migrants - screening, surveillance and ethics
}

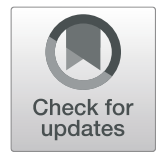

\author{
Gabriella Scandurra ${ }^{1 *}$, Chris Degeling ${ }^{2}$, Paul Douglas ${ }^{3}$, Claudia C. Dobler ${ }^{4}$ and Ben Marais ${ }^{1}$
}

\begin{abstract}
Tuberculosis (TB) is the leading infectious cause of human mortality and is responsible for nearly 2 million deaths every year. It is often regarded as a 'silent killer' because it predominantly affects the poor and marginalized, and disease outbreaks occur in 'slow motion' compared to Ebola or coronavirus 2 (COVID-19). In low incidence countries, TB is predominantly an imported disease and TB control in migrants is pivotal for countries to progress towards TB elimination in accordance with the World Health Organisations (WHO's) End TB strategy. This review provides a brief overview of the different screening approaches and surveillance processes that are in place in low TB incidence countries. It also includes a detailed discussion of the ethical issues related to TB screening of migrants in these settings and the different interests that need to be balanced. Given recognition that a holistic approach that recognizes and respects basic human rights is required to end $T B$, the review considers the complexities that require consideration in low-incidence countries that are aiming for TB elimination.
\end{abstract}

Keywords: Tuberculosis, TB, Migration, Migrants, Review, Pre-screening, Ethics

\section{Introduction}

Tuberculosis (TB), is one of the oldest airborne pathogens; found in human remains from nearly 10,000 years ago [1]. Despite its ancient history, TB remains the number one infectious disease killer on the planet (WHO report) with an estimated 10 million people developing TB every year, resulting in nearly 2 million deaths [2]. TB disproportionally affects socioeconomically disadvantaged populations living in low-and middle-income countries in Asia and Africa and is often referred to as the "silent epidemic", because of its relatively slow spread and the fact that affected populations are often 'less visible'. Mycobacterium tuberculosis, the causative organism of TB disease, is approximately 50 times slower to grow than other common bacteria, and TB disease develops more slowly than high profile viral epidemics such as Ebola or coronavirus 2 (COVID-19). Because TB mainly affects

\footnotetext{
* Correspondence: gabriella.scandurra@sydney.edu.au;

gabriella.scandurra@gmail.com

${ }^{1}$ Marie Bashir Institute for Infectious Diseases and Biosecurity, The University of Sydney, Sydney, Australia

Full list of author information is available at the end of the article
}

socioeconomically disadvantaged groups [3] (whose voice is often not heard) and appears less threatening to high-income countries than other pandemics, research progress on TB diagnostics and treatments has been slow.

Galvanized by the World Health Organization's STOP TB and END TB campaigns [4, 5], active case finding initiatives have successfully reduced the prevalence of TB $[6,7]$ and randomized control trials are informing better ways to find and treat TB cases $[8,9]$. The importance of new tools, and better ways of finding and treating all people with TB are well recognized, as is the need to address the many social, financial, ethical, and cultural barriers that limit access to TB prevention, diagnosis and care [2]. But progress requires high level political commitment and sufficient financial resources to implement solutions that have been shown to work. A holistic approach is essential to effectively tackle the many challenges posed by global TB control [10], including careful consideration of TB in migrants. Here we focus on the practice and ethics of TB screening and surveillance in migrants.

(c) The Author(s). 2020 Open Access This article is licensed under a Creative Commons Attribution 4.0 International License, which permits use, sharing, adaptation, distribution and reproduction in any medium or format, as long as you give appropriate credit to the original author(s) and the source, provide a link to the Creative Commons licence, and indicate if changes were made. The images or other third party material in this article are included in the article's Creative Commons licence, unless indicated otherwise in a credit line to the material. If material is not included in the article's Creative Commons licence and your intended use is not permitted by statutory regulation or exceeds the permitted use, you will need to obtain permission directly from the copyright holder. To view a copy of this licence, visit http://creativecommons.org/licenses/by/4.0/. 


\section{A world in motion}

Globalization while traditionally focused on trade and finance has become one of the driving factors of people movement around the world. Improvements in transportation technology, decrease in travel time and costs have been integral in changing the patterns of migration in the world today with $3.4 \%$ of the world's population residing in a country other than their county of birth (IOM). Global mobility and connectivity supports growth in international trade, exchange of ideas, new technology and social/cultural interaction, but it also increases the risk of infectious disease spread and global pandemics, as illustrated by the current severe acute respiratory syndrome COVID-19 outbreak.

\section{Transmission sustains the epidemic}

The global TB epidemic, declared by WHO as a global health emergency in 1993, is driven by ongoing transmission [11] and factors increasing population vulnerability [12], which also applies to emerging drug resistant disease [13-15]. Modelling suggests that adolescents and young adults are major drivers of TB transmission in high incidence countries [16] . During the period 2000-2017, the total number of international migrants rose from 173 million to 258 million, an increase of $49 \%$ [17].

Of the infected people who develop TB disease, the majority will become ill within 2-5 years from their most recent infection, but in some people TB disease may be many years after the last infection episode [18]. In low $\mathrm{TB}$ incidence countries where $\mathrm{TB}$ transmission is limited and most latent TB infection [LTBI] (as well as active disease) is imported from high incidence settings [19], preventing re-activation of LTBI is a major TB control strategy in migrant populations [20, 21]. However, given the high mobility and circulatory nature of migrant populations and the fact that the organism moves with people and crosses national borders with ease [22, 23], future re-infection when visiting areas of the world with poor epidemic control where most TB and drug resistant TB (DR-TB) transmission occurs [11], remains a concern.

\section{Active TB screening}

TB screening policies for migrants attempt to protect populations in low incidence countries against imported TB disease and these mainly focus on pre-migration screening of migrants prior to obtaining travel approval, as implemented by Australia, Canada, New Zealand (NZ), the United Kingdom (UK) and the United States of America (US) [24], as well as the Gulf Corporation Countries (GCC) or post-migration screening after migrants arrive in their destination country, which is predominantly the European approach [25]. A systematic review that analysed TB screening policies in 15 countries, demonstrated poor consistency of practice and standardization [26], stemming from the distinct geographies of each receiving country and different migrant entry routes. Variation in TB screening practices among migrants also reflects the lack of evidence to guide the most effective, efficient and cost-effective TB screening approaches.

Variation in national policies and practices for TB screening in migrants mainly relate to differences in risk factor assessment and different risk thresholds based on the estimated TB incidence in the country of origin [27, 28]. Discrepancies include the definition of a "high TB burden country" (ranging from 40, 60 or 100 per 100, 000 population) $[27,29]$, the intended period of stay (usually greater than 3 or 6 months) and the visa category that triggers formal TB screening and post-arrival surveillance of migrants deemed at high risk of developing TB identified during initial screening. People on refugee or humanitarian visa subclasses have often been considered as high-risk groups [28, 30], but their TB risk is highly variable and dependent on the specific refugee cohort (e.g. based on the TB incidence in the country of origin). Practices differ with some countries in Europe (like Greece and Spain) screening all asylum seekers and others (like Italy) not having any formal screening of asylum seekers [31]. Countries like Australia, screen all persons entering on humanitarian visas (which are a permanent visa category) and when determining the TB risk posed by temporary migrants in Australia, great emphasis is placed on the estimated $\mathrm{TB}$ incidence in the country of origin and their declared length of stay [32].

There are many barriers to TB screening, detection and treatment among asylum seekers and refugees, one being stigma, and these will be further discussed in the ethics section of this review. Only through data sharing and research will we acquire better evidence to guide optimal TB screening methods in migrants. Access to essential health services by refugees and migrants vary by country [33] and are determined by national law. Implementation of the improvements to migrant and refugee health, must take account of specific country situations and be in accordance with national legislation, priorities and circumstances, and international instruments on equal access to public health care services.

\section{TB surveillance and monitoring}

Electronic TB databases, such as E-detect in Europe [34] and eMedical in Australia [35] have been established for the better surveillance and epidemiological analysis to inform future TB control interventions [36]. E-detect arose from a tuberculosis consortium, shared by 6 European Union countries, Sweeden, Netherlands, UK, Italy, Romaina and Bulgaria, bringing together world leading 
TB experts in national public health agencies with industry and major academic centres to address the high disease burden of TB and multi-drug resistant TB through evidenced-based interventions, in vulnerable EU populations, including migrants [37]. E-detect is geared towards TB diagnosis and detection among new and settled asylum seekers and refugees and, importantly, linking patients into the health care system once they have been diagnosed. E-detect also provides standardized TB data from partner countries, including data on LTBI, with the goal of enhancing intercountry collaboration to support the implementation of future TB screening policies and frameworks. Participating countries collect, clean and recode data using a unique de-identified identifier on a range of TB screening data fields (country of screening, screening scheme, sex, age, country of origin, screening performed, screening results and where available, data on initiated and completed treatment), which is then uploaded to the shared database [34]. This allows analysis of best practice from countries where national strategic plans have been most effective, aiding the development of shared and optimised frameworks for enhanced TB control.

E-detect can also be linked with the E-Detect TB smartphone App to assist active case finding among contacts and detect co-prevalent cases [38]. Rapid 'digital screening' via a mobile device supports the rapid identification and testing of those individuals who require prioritization for sputum collection and Xpert Ultra ${ }^{\circ}$ testing. Use of this system have been shown to assist earlier diagnosis and the direct transfer of relevant patient information to referral hospitals in Italy, improving the overall cascade of care in vulnerable and marginalized migrant communities [38].

In Australia, the eMedical database of the Department of Home Affairs collects all TB health information of migrating individuals from the health screening process conducted pre- or post-migration [35]. The database has particular value to identify migrants at high risk of developing TB post-arrival, for example if a lung lesion consistent with TB is detected during initial chest radiography screening, but without microbiological proof of active TB disease. These migrants will undergo ongoing surveillance for disease development or receive preventive TB treatment post-arrival once active disease has been ruled out [39]. Migrants at high risk of developing TB enter into a legally binding agreement as a specific condition of a visa to comply with TB surveillance conducted by local TB health services, referred to as a 'TB undertaking'. Similarly, electronic databases used by Canada, NZ, and the US, collect information including country of origin, date of birth, gender, occupation, visa details, health data including self-declaration on TB symptoms, previous TB contact, results of chest radiographs, diagnostic test results from sputum smear or culture, treatment regimens and medical follow-up from migrants. This information is vital for TB control with the goal to eventually eliminate TB $[21,40,41]$.

Whole genome sequencing (WGS) provides excellent M. tuberculosis strain resolution in order to differentiate imported from locally transmitted strains and strain clusters [42-46]. Australia's most populous state New South Wales implemented routine WGS of all cultureconfirmed TB cases in 2016, which guided better targeted public health responses and confirmed that local transmission is limited [12, 47, 48]. WGS provides valuable information to assist individual patient management and public health responses, but widespread implementation in resource-limited settings remains unrealistic at present. Enhanced polymerase chain reaction (PCR) based methods may be more feasible in the interim, both for genetic drug resistance determination and transmission tracking [49]. In time, the establishment of global TB surveillance systems will complement epidemiological surveillance and could track cross-border transmission dynamics, but also pose risks to personal freedom that should be considered (see Ethics section).

\section{LTBI screening}

Acknowledging that LTBI provides a reservoir of infection from which future TB cases may arise [50], lowincidence countries have increasingly implemented LTBI screening among migrants, either pre-departure or post arrival $[24,51]$. According to a survey of policies in 29 Organisation for Economic Cooperation and Development (OECD) countries, 16 countries (55\%) routinely screened migrants for LTBI [52]. Target populations for LTBI screening vary by age and the country of origin. Australia, and the US only screen migrant children (aged up to 10 years for Australia and up to 15 years for US) for LTBI, as a marker of possible TB disease that justifies a chest radiograph if positive. Testing for LTBI is done using a traditional tuberculin skin test (TST) or an interferon-gamma release assay (IGRA), which has higher specificity.

In a Taiwanese study, the highest number of TB cases found among migrants were identified less than 2 years after migration in individuals who had a clear chest radiograph at initial TB screening [53]. In other settings, the documented risk of LTBI reactivation is elevated in migrants who have fibrotic scars $\geq 2 \times 2 \mathrm{~cm}$ and/or calcified nodules $\geq 1.5 \mathrm{~mm}$ on chest radiograph consistent with previous TB infection [24, 54, 55]. An Australian study found that $1.3 \%$ of migrants (428/32,550 migrants) deemed to be at a high risk of developing TB based on pre-migration screening (mainly because of chest radiograph abnormalities) developed TB [39]. Of these TB cases, 270 (63\%) were diagnosed during active TB 
follow-up in the first 2 years post migration; the period of their 'TB undertaking'.

Treating high risk migrants for LTBI, once TB disease has been ruled out, should benefit individual migrants and the general public [56], although formal cost effectiveness analyses remain limited. A systematic review of 16 studies on LTBI screening among migrants did not arrive at any definite conclusions about the (cost-) effectiveness of this intervention [57]. The (cost-) effectiveness of LTBI screening and treatment among migrants was limited by the high number of migrants lost at some level of the care cascade and the fact that only a small number completed LTBI treatment. A modelling study showed that pre-migration screening using an IGRA combined with post-arrival treatment with 4 months of rifampicin among migrants from countries with moderate to high $\mathrm{TB}$ incidence resulted in the best cost-effectiveness ratios [58].

With increased global mobility, a growing number of short-term migrants enter low $\mathrm{TB}$ incidence countries repeatedly without $\mathrm{TB}$ screening, because their intended period of stay is less than the specified cut-off triggering such a requirement. It is unclear to what extent these temporary migrants might contribute to TB disease importation, but the benefits of screening and treating these migrants for LTBI would likely be diminished by ongoing TB exposure in their countries of origin. The legitimacy of pre-migration TB screening has been questioned, $[59,60]$ with some arguing that better primary care should be available for migrants to support their general health and wellbeing, as well as early TB identification. Patient-centered approaches to TB care have been shown to reduce diagnostic delay, with likely reduction in $\mathrm{TB}$ transmission, and improve treatment outcome in migrants [61]. We explore some of the tensions between the classic public health and social dimensions of the problem, as well as the resultant ethical dilemmas in greater detail.

\section{Ethical dimensions}

The TB status of migrants has normative dimensions because of the potential health impacts to individuals and others, and the associated limitations a positive diagnosis can have on their movements within and between countries. Ethical issues related to migrant TB screening are briefly discussed and summarised in Table 1. TB screening of migrants should mainly be justified on the basis of providing appropriate medical care [62]. Being diagnosed with TB or LTBI can serve as a point of discrimination, which can impinge upon the opportunities and choices available to individuals, and increase the risk of harms through TB-related health inequities and social stigma. Current conceptualizations of stigma identify two basic forms [63]. 'Enacted TB stigma' refers to exclusion, rejection or devaluation by others based on beliefs of social unacceptability. 'Perceived TB stigma' refers to patient and family fears of inferiority stemming from the anticipation of an adverse judgment related to a TB diagnosis. Both cause harms to individuals and groups and are recognized to be a significant barrier to health care utilization and adherence to TB treatment $[64,65]$. Consequently, as is the case with all other TB patients, the privacy and confidentiality of migrants using TB services needs to be protected at all times [62].

Unfortunately, historical TB control efforts frequently entwined immigration and public health law, which exacerbated stigma and xenophobia and requires constant vigilance $[66,67]$. Under these conditions TB screening

Table 1 Overview of ethical issues related to migrant TB screening

\begin{tabular}{|c|c|}
\hline Issues identified & Key considerations \\
\hline Care obligation linked to TB screening & The human rights issue of providing appropriate medical care to all people, irrelevant of TB or LTBI \\
\hline \multicolumn{2}{|l|}{ Stigma } \\
\hline Enacted TB stigma & Exclusion, rejection or devaluation by others based on beliefs of inferiority or social unacceptability \\
\hline Perceived TB stigma & $\begin{array}{l}\text { Patient and family fears of inferiority stemming from the anticipation of an adverse judgment } \\
\text { related to a TB diagnosis }\end{array}$ \\
\hline "At-risk group" stigma & $\begin{array}{l}\text { Magnify a migrants sense of being "out of place". This requires careful attention to appropriate } \\
\text { service design and communication strategies. How best to communicate with migrants to inform } \\
\text { them about the potential benefits and risks of TB and LTBI screening requires more research. }\end{array}$ \\
\hline Privacy and confidentiality & Needs to be respected and protected at all times \\
\hline Racial vilification & $\begin{array}{l}\text { Irresponsible media reporting of TB in migrants is implicated in the production of stigma and } \\
\text { should be avoided; and racial vilification banned/censored on social media }\end{array}$ \\
\hline Health equity & $\begin{array}{l}\text { All migrants (whether they have TB or otherwise) should have access to basic health services } \\
\text { that are both medically and culturally appropriate. }\end{array}$ \\
\hline Trust in the health care system/provider & $\begin{array}{l}\text { Migrants come from countries with weak health systems and often mistrust health systems. } \\
\text { Building trust is essential to build constructive and respectful relationships between service } \\
\text { providers and migrant communities. }\end{array}$ \\
\hline
\end{tabular}


is not politically benign, but has broad consequences for those being targeted to participate. Concerns about the public health aspects of migration processes increasing the risk of racial vilification are not insignificant, as several studies suggest that TB control measures and representations of migrants in the media as agents of disease may exacerbate stigma [68]. A systematic review of qualitative studies indicates feelings of stigmatization derived from being labelled as a member of an "at-risk group" for TB by health services in their new country of residence, can further magnify migrants sense of being "out of place" [69].

Little research has focused on the specific experience of new migrants, nor sought their views on the best ways forward. For those organizing TB programmes and migration processes, key decisions need to be made as to the most appropriate setting for migration related $\mathrm{TB}$ screening and how best to communicate with migrant groups about the potential benefits and risks of these activities [70]. Whether TB screening is conducted premigration, as a mandatory part of standard immigration processes, or provided as a non-mandated service, before or after arrival in the new country, distributes the burdens of testing and TB diagnosis differently. Respect for human rights means that participation in health screening should be voluntary - to the extent that competent individuals should always be acting autonomously on the basis of their informed preferences. Nevertheless, some forms of coercion can be ethically justified if they promote significant benefits for the wider population [71, 72]. Because earlier TB case identification will reduce the future population burden of TB disease, screening that is linked to entry or legalizing residence can achieve this aim by potentially identifying and treating immigrants with $\mathrm{TB}$ at the earliest time point to prevent transmission within the recipient/host country. However, the use of these mechanisms to enforce participation and potentially transfer screening costs should be carefully considered to minimize harm and creates responsibilities for immigration authorities.

Because access to health care in countries of origin may be limited, it can be challenging for immigration authorities to meet migrants' health needs if premigration treatment is required. Coercion in the context of TB screening can also be counter-productive if it is not accompanied by clear communication about the implications of the diagnosis, the disease or the LTBI detection [73] People will ignore or doubt the importance and purpose of $\mathrm{TB}$ screening if the reasons they are given for participation are at odds with their worldviews, values, or both [74]. Poor communication and a failure to accommodate the values of those being targeted can lead to non-compliance and subsequent treatment failure. When treatment is undertaken in the recipient/host country, uncertainty about an individual's legal status may exacerbate problems of health care access [65]. Challenges faced by migrants such as communication problems, loss of social support, discrimination and acculturation can be aggravated by stigma and other sociocultural impacts of a positive TB diagnosis [75]. Nevertheless, because of health equity, social justice and public health concerns, it is important that all migrants (whether they have TB or otherwise) have access to basic health services that are both medically and culturally appropriate $[76,77]$.

As outlined above, the implementation of TB screening often results in conflicting interests and creates a tension between the obligation of the state to protect the health of the public on one hand, and respecting the autonomy, health interests, and liberty of the screened individuals on the other. Screening also creates obligations on the screener to ensure that participants are properly supported and have pathways to address detected abnormalities [78]. Screening should only be undertaken with the intention to treat and with an appropriate level of counselling ahead of such screening. The principle of reciprocity is important to guide the inclusion of certain 'migrant rights' into screening guidelines. Screening creates a two-way obligation, upon migrants to actively participate in the programme, and upon authorities to reciprocate the migrants' participation and the benefits for the control of public health [79].

In considering these background conditions, trust is an important requirement for appropriate service design and delivery for TB screening. Trust is also central to effective communication because it can initiate or build constructive and respectful relationships between service providers and migrant communities. Migrants often come from countries with weak health systems so may not trust providers or be encultured to seek professional health advice [65]. To engender trustworthiness, there is a need for clarity from service providers as to whom any migration-related screening programme is designed to benefit and the rationale underpinning decisions about how resulting burdens are distributed [78]. When considering the benefits and burdens of $\mathrm{TB}$ screening, the potential for stigma must be a key concern. TB stigma commonly arises from public health responses to TB in ways that influence affected populations as well as relevant institutions [80-83]. This is not to say that manifestations of stigma are inevitable; careful attention to appropriate service design and communication strategies can work to mitigate these impacts and risks [74]. Systematic evaluations indicate that the optimum approach in high-migrant receiving countries is to offer screening in a range of settings, incorporating a strong focus on community engagement and partnership with migrant organisations in both the design and implementation of 
screening approaches $[65,75]$. Such programmes should ensure that access to diagnostics and treatment are free of charge to maximise access and adherence.

\section{Conclusion}

Aiming for TB elimination in countries where TB is essentially an imported disease requires careful consideration of migrant populations' best interests and what a holistic TB response should look like. Particular areas requiring better evidence-based solutions include 1) objective and pragmatic risk stratification approaches, 2) better screening and diagnostic tools, and 3) optimal management of LTBI in situations where disease risk is low or the risk of future re-infection high [84, 85]. Given near-total travel bans implemented in the wake of the COVID-19 epidemic, it is an opportune time to critically reconsider and refine migration policies as borders begin to re-open.

\section{Abbreviations}

TB: Tuberculosis; DR-TB: Drug resistant TB; LTBI: Latent tuberculosis infection; IOM: International organisation for migration; WHO: World health organisation; TST: Tuberculin skin test; IGRA: Interferon-gamma release assay; COVID-19: Coronavirus 2; NZ: New Zealand; UK: United Kingdom; US: United States of America; GCC: Gulf Corporation Countries; WGS: Whole genome sequencing; PCR: Polymerase chain reaction; OECD: Organisation for Economic Cooperation and Development

\section{Acknowledgements}

None

\section{Authors' contributions}

BM and GS conceived the idea of the manuscript. All authors contributed to the planning. GS led the literature search and wrote the manuscript with CDegeling. CDobler, BM and PD appraised and contributed to the manuscript by revising the different versions. All authors read and approved the final version of the manuscript.

\section{Funding}

No funding.

\section{Availability of data and materials}

Not applicable.

\section{Ethics approval and consent to participate}

Not applicable.

\section{Consent for publication}

Not applicable.

\section{Competing interests}

The authors declare that they have no competing interests.

\section{Author details}

'Marie Bashir Institute for Infectious Diseases and Biosecurity, The University of Sydney, Sydney, Australia. ${ }^{2}$ Australian Centre for Health Engagement Evidence and Values, University of Wollongong, Wollongong, Australia. ${ }^{3}$ International Organization for Migration (IOM), Geneva, Switzerland. ${ }^{4}$ Institute for Evidenced-Based Healthcare, Bond University, Gold Coast, Australia.
Received: 28 June 2020 Accepted: 29 July 2020

Published online: 05 September 2020

\section{References}

1. Chisholm RH, Trauer JM, Curnoe D, Tanaka MM. Controlled fire use in early humans might have triggered the evolutionary emergence of tuberculosis. Proc Natl Acad Sci U S A. 2016:113(32):9051-6.

2. World Health Organisation. Global tuberculosis report. 2019

3. Benatar SR, Upshur R. Tuberculosis and poverty: what could (and should) be done? Int J Tuberc Lung Dis. 2010;14(10):1215-21.

4. World Health Organisation. The stop TB strategy. World Health Organisation; 2006.

5. World Health Organisation. The end TB strategy: World Health Organisation; 2014.

6. Marks GB, Nguyen NV, Nguyen PTB, Nguyen TA, Nguyen HB, Tran KH, et al. Community-wide screening for tuberculosis in a high-prevalence setting. $\mathrm{N}$ Engl J Med. 2019;381(14):1347-57.

7. Ho J, Fox GJ, Marais BJ. Passive case finding for tuberculosis is not enough. Int J Mycobacteriol. 2016;5(4):374-8.

8. Saunders MJ, Tovar MA, Collier D, Baldwin MR, Montoya R, Valencia TR, et al. Active and passive case-finding in tuberculosis-affected households in Peru: a 10-year prospective cohort study. Lancet Infect Dis. 2019;19(5):519-28.

9. Fox GJ, Nhung NV, Marks GB. Household-contact investigation for detection of tuberculosis in Vietnam. N Engl J Med. 2018;378(22):2141.

10. Lonnroth K, Jaramillo E, Williams BG, Dye C, Raviglione M. Drivers of tuberculosis epidemics: the role of risk factors and social determinants. Soc Sci Med. 2009;68(12):2240-6.

11. Ragonnet R, Trauer JM, Denholm JT, Marais BJ, McBryde ES. High rates of multidrug-resistant and rifampicin-resistant tuberculosis among re-treatment cases: where do they come from? BMC Infect Dis. 2017;17(1):36.

12. Marais BJ, Lonnroth K, Lawn SD, Migliori GB, Mwaba P, Glaziou P, et al. Tuberculosis comorbidity with communicable and non-communicable diseases: integrating health services and control efforts. Lancet Infect Dis. 2013;13(5):436-48.

13. Biadglegne F, Rodloff AC, Sack U. Review of the prevalence and drug resistance of tuberculosis in prisons: a hidden epidemic. Epidemiol Infect. 2015:143(5):887-900

14. Abubakar I, Zignol M, Falzon D, Raviglione M, Ditiu L, Masham S, et al. Drugresistant tuberculosis: time for visionary political leadership. Lancet Infect Dis. 2013;13(6):529-39.

15. World Health Organisation. Global tuberculosis report 2018. World Health Organisation.

16. Ragonnet R, Trauer JM, Geard N, Scott N, McBryde ES. Profiling mycobacterium tuberculosis transmission and the resulting disease burden in the five highest tuberculosis burden countries. BMC Med. 2019;17(1):208.

17. United Nations. Populaton facts: United Nations, Department of Economic and Social Affairs, Division P; 2017.

18. Dale KD, Trauer JM, Dodd PJ, Houben R, Denholm JT. Estimating long-term tuberculosis reactivation rates in Australian migrants. Clin Infect Dis. 2019: 70(10):2111-8

19. Marais BJ, Walker TM, Cirillo DM, Raviglione M, Abubakar I, van der Werf MJ, et al. Aiming for zero tuberculosis transmission in low-burden countries. Lancet Respir Med. 2017;5(11):846-8.

20. Pareek M, Greenaway C, Noori T, Munoz J, Zenner D. The impact of migration on tuberculosis epidemiology and control in high-income countries: a review. BMC Med. 2016:14:48.

21. Lonnroth K, Migliori GB, Abubakar I, D'Ambrosio L, de Vries G, Diel R, et al. Towards tuberculosis elimination: an action framework for low-incidence countries. Eur Respir J. 2015;45(4):928-52.

22. Pescarini JM, Rodrigues LC, Gomes MG, Waldman EA. Migration to middleincome countries and tuberculosis-global policies for global economies. Glob Health. 2017;13(1):15.

23. Saker L, Lee K, Cannito B, Campbell-Lendrum D. Globalization and infectious diseases: a review of the linkages: World Health Organization; 2004.

24. Dobler CC, Fox GJ, Douglas P, Viney KA, Ahmad Khan F, Temesgen Z, et al. Screening for tuberculosis in migrants and visitors from high-incidence settings: present and future perspectives. Eur Respir J. 2018:52(1):1800591.

25. Coker R, Bell A, Pitman R, Zellweger JP, Heldal E, Hayward A, et al. Tuberculosis screening in migrants in selected European countries shows wide disparities. Eur Respir J. 2006;27(4):801-7. 
26. Garner-Purkis A, Hine P, Gamage A, Perera S, Gulliford MC. Tuberculosis screening for prospective migrants to high-income countries: systematic review of policies. Public Health. 2019;168:142-7.

27. Cobelens FG, van Deutekom H, Draayer-Jansen IW, Schepp-Beelen AC, van Gerven PJ, van Kessel RP, et al. Risk of infection with mycobacterium tuberculosis in travellers to areas of high tuberculosis endemicity. Lancet. 2000;356(9228):461-5.

28. Lonnroth K, Mor Z, Erkens C, Bruchfeld J, Nathavitharana RR, van der Werf MJ, et al. Tuberculosis in migrants in low-incidence countries: epidemiology and intervention entry points. Int J Tuberc Lung Dis. 2017;21(6):624-37.

29. Bozorgmehr K, Preussler S, Wagner U, Joggerst B, Szecsenyi J, Razum O, et al. Using country of origin to inform targeted tuberculosis screening in asylum seekers: a modelling study of screening data in a German federal state, 2002-2015. BMC Infect Dis. 2019;19(1):304.

30. Liu Y, Weinberg MS, Ortega LS, Painter JA, Maloney SA. Overseas screening for tuberculosis in U.S.-bound immigrants and refugees. N Engl J Med. 2009 360(23):2406-15.

31. Kunst H, Burman M, Arnesen TM, Fiebig L, Hergens MP, Kalkouni O, et al Tuberculosis and latent tuberculous infection screening of migrants in Europe: comparative analysis of policies, surveillance systems and results. Int J Tuberc Lung Dis. 2017;21(8):840-51.

32. The Department of Home Affairs. Tuberculosis 2020 [20th April 2020]. Available from: https://immi.homeaffairs.gov.au/help-support/meeting-ourrequirements/health/threats-to-public-health. Accessed 24 Jan 2020.

33. World Health Organisation. World Health assembly. 2019;A72/25 Rev.1.

34. Ohd JN, Lonnroth K, Abubakar I, Aldridge RW, Erkens C, Jonsson J, et al. Building a European database to gather multi-country evidence on active and latent TB screening for migrants. Int J Infect Dis. 2019;80S:S45-S9.

35. The Department of Home Affairs. E-medical 2020 [updated 17th March 2020. Available from: https://immi.homeaffairs.gov.au/help-support/meetingour-requirements/health/your-health-examinations-appointment. Accessed 24 Jan 2020.

36. TB UoCL. Establishing a European TB database 2020 [updated 23 May 2020. Available from: https://e-detecttb.eu/2017/05/23/establishing-a-european-tbdatabase/. Accessed 4 Apr 2020.

37. Abubakar I, Matteelli A, de Vries G, Zenner D, Cirillo DM, Lonnroth K, et al. Towards tackling tuberculosis in vulnerable groups in the European Union: the E-DETECT TB consortium. Eur Respir J. 2018;51(5):1702604.

38. Barcellini L, Borroni E, Cimaglia C, Girardi E, Matteelli A, Marchese V, et al. App-based symptoms screening with Xpert MTB/RIF ultra assay used for active tuberculosis detection in migrants at point of arrivals in Italy: the $\mathrm{E}$ DETECT TB intervention analysis. PLoS One. 2019;14(7):e0218039.

39. Kaushik N, Lowbridge C, Scandurra G, Dobler CC. Post-migration follow-up programme for migrants at increased risk of developing tuberculosis: a cohort study. ERJ Open Res. 2018;4(3). https://doi.org/10.1183/23120541. 00008-2018.

40. Harding E. WHO global progress report on tuberculosis elimination. Lancet Respir Med. 2020;8(1):19.

41. National Tuberclosis Advisory Committee. Strategic plan for control of tuberculosis in Australia 2016-2020: towards disease elimination. 2018.

42. Folkvardsen DB, Norman A, Rasmussen EM, Lillebaek T, Jelsbak L, Andersen $A B$. Recurrent tuberculosis in patients infected with the predominant mycobacterium tuberculosis outbreak strain in Denmark. New insights gained through whole genome sequencing. Infect Genet Evol. 2020;80: 104169.

43. Fiebig L, Kohl TA, Popovici O, Muhlenfeld M, Indra A, Homorodean D, et al. A joint cross-border investigation of a cluster of multidrug-resistant tuberculosis in Austria, Romania and Germany in 2014 using classic genotyping and whole genome sequencing methods: lessons learnt. Euro Surveill. 2017;22(2):30439

44. Diel R, Kohl TA, Maurer FP, Merker M, Meywald Walter K, Hannemann J, et al. Accuracy of whole-genome sequencing to determine recent tuberculosis transmission: an 11-year population-based study in Hamburg, Germany. Eur Respir J. 2019;54(5):1901154.

45. Stucki D, Ballif M, Bodmer T, Coscolla M, Maurer AM, Droz S, et al. Tracking a tuberculosis outbreak over 21 years: strain-specific single-nucleotide polymorphism typing combined with targeted whole-genome sequencing. J Infect Dis. 2015;211(8):1306-16.

46. Meehan CJ, Goig GA, Kohl TA, Verboven L, Dippenaar A, Ezewudo M, et al. Whole genome sequencing of mycobacterium tuberculosis: current standards and open issues. Nat Rev Microbiol. 2019;17(9):533-45.
47. Gurjav U, Jelfs P, McCallum N, Marais BJ, Sintchenko V. Temporal dynamics of mycobacterium tuberculosis genotypes in New South Wales, Australia. BMC Infect Dis. 2014;14:455.

48. Gurjav U, Jelfs P, Hill-Cawthorne GA, Marais BJ, Sintchenko V. Genotype heterogeneity of mycobacterium tuberculosis within geospatial hotspots suggests foci of imported infection in Sydney, Australia. Infect Genet Evol. 2016;40:346-51

49. Abascal E, Perez-Lago L, Martinez-Lirola M, Chiner-Oms A, Herranz M, Chaoui I, et al. Whole genome sequencing-based analysis of tuberculosis (TB) in migrants: rapid tools for cross-border surveillance and to distinguish between recent transmission in the host country and new importations. Euro Surveill. 2019;24(4):1800005.

50. Rangaka MX, Cavalcante SC, Marais BJ, Thim S, Martinson NA, Swaminathan $\mathrm{S}$, et al. Controlling the seedbeds of tuberculosis: diagnosis and treatment of tuberculosis infection. Lancet. 2015;386(10010):2344-53.

51. Chan IHY, Kaushik N, Dobler CC. Post-migration follow-up of migrants identified to be at increased risk of developing tuberculosis at premigration screening: a systematic review and meta-analysis. Lancet Infect Dis. 2017;17(7):770-9.

52. Pareek M, Baussano I, Abubakar I, Dye C, Lalvani A. Evaluation of immigrant tuberculosis screening in industrialized countries. Emerg Infect Dis. 2012; 18(9):1422-9.

53. Kuan MM. Nationwide surveillance algorithms for tuberculosis among immigrant workers from highly endemic countries following pre-entry screening in Taiwan. BMC Public Health. 2018;18(1):1151.

54. Pareek M, Abubakar I, White PJ, Garnett GP, Lalvani A. Tuberculosis screening of migrants to low-burden nations: insights from evaluation of UK practice. Eur Respir J. 2011;37(5):1175-82.

55. Uzorka JW, Kroft LJM, Bakker JA, van Zwet EW, Huisman E, Prins C, et al Abnormalities suggestive of latent tuberculosis infection on chest radiography; how specific are they? J Clin Tuberc Other Mycobact Dis. 2019; 15:100089.

56. Dobler CC, Martin A, Marks GB. Benefit of treatment of latent tuberculosis infection in individual patients. Eur Respir J. 2015:46(5):1397-406.

57. Greenaway C, Pareek M, Abou Chakra CN, Walji M, Makarenko I, Alabdulkarim B, et al. The effectiveness and cost-effectiveness of screening for active tuberculosis among migrants in the EU/EEA: a systematic review. Euro Surveill. 2018;23(14):17-00543.

58. Campbell JR, Johnston JC, Cook VJ, Sadatsafavi M, Elwood RK, Marra F. Costeffectiveness of latent tuberculosis infection screening before immigration to low-incidence countries. Emerg Infect Dis. 2019;25(4):661-71.

59. Coker R. Compulsory screening of immigrants for tuberculosis and HIV. BMJ. 2004:328(7435):298-300.

60. Bempong NE, Sheath D, Seybold J, Flahault A, Depoux A, Saso L. Critical reflections, challenges and solutions for migrant and refugee health: 2 nd M8 Alliance expert meeting. Public Health Rev. 2019;40:3.

61. Mazza-Stalder J, Chevallier E, Opota O, Carreira A, Jaton K, Masserey E, et al. Improvement in tuberculosis outcomes with a combined medical and social approach. Front Med (Lausanne). 2019:6:135.

62. World Health Organisation. Ethics guidance for the implementation of the END TB strategy. 2017

63. Van Brakel WH. Measuring health-related stigma--a literature review. Psychol Health Med. 2006:11(3):307-34.

64. Courtwright A, Turner AN. Tuberculosis and stigmatization: pathways and interventions. Public Health Rep. 2010:125(Suppl 4):34-42.

65. de Vries SG, Cremers AL, Heuvelings CC, Greve PF, Visser BJ, Belard S, et al. Barriers and facilitators to the uptake of tuberculosis diagnostic and treatment services by hard-to-reach populations in countries of low and medium tuberculosis incidence: a systematic review of qualitative literature. Lancet Infect Dis. 2017;17(5):e128-e43.

66. Welshman J, Bashford A. Tuberculosis, migration, and medical examination: lessons from history. J Epidemiol Community Health. 2006;60(4):282-4.

67. Horner JWJ, Kelly A. Public health in/as 'national security': tuberculosis and the contemporary regime of border control in Australia. Crit Public Health. 2013;23(4):418-31

68. Craig GM, Daftary A, Engel N, O'Driscoll S, loannaki A. Tuberculosis stigma as a social determinant of health: a systematic mapping review of research in low incidence countries. Int J Infect Dis. 2017:56:90-100.

69. Abarca Tomas B, Pell C, Bueno Cavanillas A, Guillen Solvas J, Pool R, Roura M. Tuberculosis in migrant populations. A systematic review of the qualitative literature. PLoS One. 2013;8(12):e82440. 
70. Degeling C, Carroll J, Denholm J, Marais B, Dawson A. Ending TB in Australia: organizational challenges for regional tuberculosis programs. Health Policy. 2020;124(1):106-12.

71. Coker R. Migration, public health and compulsory screening for TB and: Hiv: Institute for Public Policy Research; 2004.

72. Juth NMC. The ethics of screening in health care and medicine: serving society or serving the patient? Springer Netherlands; 2011.

73. Klinkenberg E, Manissero D, Semenza JC, Verver S. Migrant tuberculosis screening in the EU/EEA: yield, coverage and limitations. Eur Respir J. 2009; 34(5):1180-9.

74. Guttman N, Salmon CT. Guilt, fear, stigma and knowledge gaps: ethical issues in public health communication interventions. Bioethics. 2004;18(6): $531-52$.

75. Brewin P, Jones A, Kelly M, McDonald M, Beasley E, Sturdy P, et al. Is screening for tuberculosis acceptable to immigrants? A qualitative study. J Public Health (Oxf). 2006;28(3):253-60.

76. Wickramage K, Mosca D. Can migration health assessments become a mechanism for global public health good? Int J Environ Res Public Health. 2014;11(10):9954-63.

77. Verina W. Universal access to health care for migrants: applying cosmopolitanism to the domestic realm. Public Health Ethics. 2015;8(2):10.

78. Degeling C, Denholm J, Mason P, Kerridge I, Dawson A. Eliminating latent tuberculosis in low-burden settings: are the principal beneficiaries to be disadvantaged groups or the broader population? J Med Ethics. 2017;43(9): 632-6.

79. Beeres DT, Cornish D, Vonk M, Ravensbergen SJ, Maeckelberghe ELM, Boele Van Hensbroek P, et al. Screening for infectious diseases of asylum seekers upon arrival: the necessity of the moral principle of reciprocity. BMC Med Ethics. 2018;19(1):16

80. Chang SH, Cataldo JK. A systematic review of global cultural variations in knowledge, attitudes and health responses to tuberculosis stigma. Int J Tuberc Lung Dis. 2014;18(2):168-73 i-iv.

81. Turan JM, Elafros MA, Logie CH, Banik S, Turan B, Crockett KB, et al. Challenges and opportunities in examining and addressing intersectional stigma and health. BMC Med. 2019;17(1):7.

82. Seedat $F$, Hargreaves S, Friedland JS. Engaging new migrants in infectious disease screening: a qualitative semi-structured interview study of UK migrant community health-care leads. PLoS One. 2014;9(10):e108261.

83. Courtwright ATA. Tuberculosis and stigmatization: pathways and interventions. Public Health Rep. 2010;125(2 Suppl):8.

84. Fox GJ, Dobler CC, Marais BJ, Denholm JT. Preventive therapy for latent tuberculosis infection-the promise and the challenges. Int J Infect Dis. 2017; 56:68-76.

85. Petersen E, Maeurer M, Marais B, Migliori GB, Mwaba P, Ntoumi F, et al. World TB day 2017: advances, challenges and opportunities in the "end-TB" era. Int J Infect Dis. 2017:56:1-5.

\section{Publisher's Note}

Springer Nature remains neutral with regard to jurisdictional claims in published maps and institutional affiliations.

Ready to submit your research? Choose BMC and benefit from:

- fast, convenient online submission

- thorough peer review by experienced researchers in your field

- rapid publication on acceptance

- support for research data, including large and complex data types

- gold Open Access which fosters wider collaboration and increased citations

- maximum visibility for your research: over $100 \mathrm{M}$ website views per year

At $\mathrm{BMC}$, research is always in progress.

Learn more biomedcentral.com/submissions 